\title{
THE SMALL PULMONARY VESSELS IN MITRAL STENOSIS
}

\author{
BY \\ EDWIN W. HENRY \\ From the Institute of Pathology, Belfast \\ Received February 11, 1952
}

The association of pulmonary arteriosclerosis with mitral stenosis has long been recognized: Posselt (1909) reviewing all the cases of pulmonary arteriosclerosis published in the 19th century found that mitral stenosis was present in $\mathbf{4 0}$ per cent of them. In early accounts, however, attention was directed only to atheroma of the main pulmonary arterial branches, and later descriptions of changes in the small intrapulmonary vessels are difficult to interpret because of differences in terminology. Brenner (1935) gave an excellent account of the morphology of the pulmonary vasculature and his definitions have been adhered to in this paper.

In view of the increasing number of cases of mitral stenosis treated by valvulotomy it is important to define exactly the changes occurring in the small pulmonary vessels to decide whether such changes are likely to continue obstructing the blood flow after operation. The small pulmonary arteries, arterioles, venules, and small veins have been examined in the present investigation, since thickening of the wall of these vessels is likely to bring about significant narrowing of the total vascular lumen.

Material and methods. Sections of the lung from 105 cases of mitral stenosis coming to autopsy in this department in the last 14 years were examined microscopically. As far as possible sections from two separate blocks were prepared in each case and stained by Hart's method for elastic tissue and van Gieson's connective tissue stain. Selected sections were stained with Masson's trichrome stain. Sections were examined in random order and without reference to other details of the case. Changes observed in small arteries, arterioles, venules, and small veins were recorded. The part of the lung from which the original blocks had been taken was unknown. Details of each case were obtained from autopsy records. Right ventricular hypertrophy was considered to be present when a thickness of $5 \mathrm{~mm}$. or more had been recorded. The degree of mitral stenosis was divided into four groups (1) slight or doubtful, admitting two fingers with difficulty, (2) moderate, admitting one finger, (3) severe, admitting one fingertip, and (4) gross, not admitting the tip of the little finger.

In addition, 70 control cases were selected from routine autopsy records, 10 from each of second to eighth decades (inclusive), and divided in the proportion of 4 men to 6 women (the approximate relationship between the sexes in the mitral stenosis series). Chronic pulmonary and cardiovascular-renal disease were excluded from the control series as being possibly associated with some degree of pulmonary hypertension. Sections from the lungs of these cases were examined in the manner previously detailed. Three cases were excluded following microscopic examination since conditions that might be associated with pulmonary hypertension were present although not adequately emphasized in the records.

\section{RESUlTS}

Of the 105 cases of mitral stenosis examined 42 were men and 63 women. The age at death ranged from 15-79 years. (Decades: II-6; III-15; IV-22; V-32; VI-15; VII-9; VIII-6). All cases over 50 showed something more than the narrowing of the mitral orifice, e.g. adherence of valve cusps, calcification, or vascularization of leaflets. 
The degree of mitral stenosis was slight or doubtful in 9 cases, moderate in 48 , severe in 33 , and gross in 10 cases. In 5 the degree of mitral stenosis had not been recorded at autopsy. Right ventricular hypertrophy was present in 56 cases, absent in 25 , and had not been recorded in 24 cases.

Arterioles and Venules. Normal pulmonary arterioles (Brenner, 1935) are indistinguishable from pulmonary venules, both being below $0.1 \mathrm{~mm}$. in external diameter and consisting of a single elastic lamina enclosing an endothelial tube (Fig. 1). Occasional muscle cells are present in interstices in the elastic layer. In some cases of mitral stenosis vessels of these dimensions were seen to have a more or less well-defined media bounded externally by a thick elastic lamina like that forming the wall of the normal arteriole and internally in most cases by a more faintly staining subendothelial elastic fibril (Fig. 2). The appearance was not so regular as that of the small muscular arteries where the external and internal elastic laminæ were of about equal thickness and depth of staining (Fig. 4). In longitudinal section the thickness of the wall varied abruptly along the course of the vessel. The media consisted of circularly directed muscle fibres with occasional strands of collagen and branching fibrils of elastic tissue.

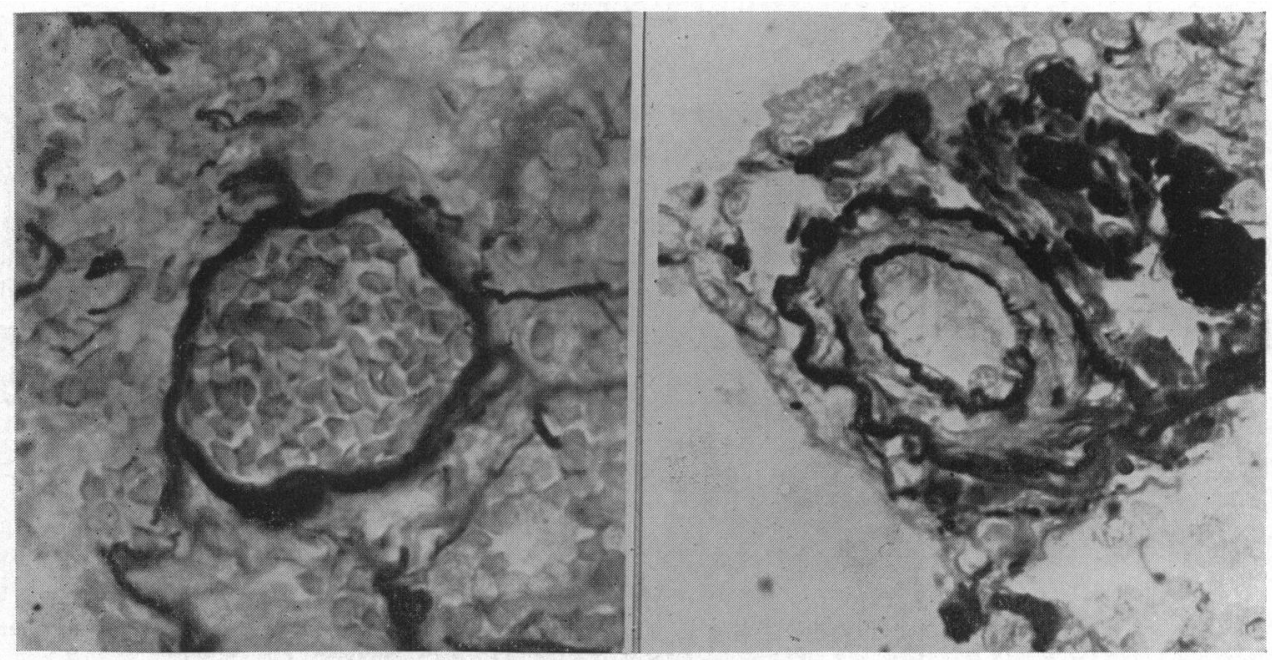

Fig. 1.-Normal pulmonary arteriole. The wall consists of a single elastic lamina. $\times 700$ : Hart-van Gieson.

FIG. 2.-Muscularized arteriole in a case of mitral stenosis. A well defined muscular media and internal elastica can be seen. $\times 700$ : Hart-van Gieson.

Other vessels of this size showed thickening of the wall due to fibrous tissue intervening between the elastic lamina and the endothelium (Fig. 3). In every section examined some arterioles and venules retained their normal structure. In many cases varying proportions of both the above changes were seen. Examination of the control cases failed to reveal any muscularization of the arterioles, but fibrous intimal thickening, of as great severity in some instances, was observed.

Table I gives the proportion of cases showing arteriolar or venular change in each series and relates these to the age at death (in two groups of $11-40$ and $41-80$ years). The type of change is recorded only when it was diffuse and readily identifiable. Cases showing both types of change are recorded as of " mixed " morphology. 40 per cent of mitral stenosis cases showed muscularization of pulmonary arterioles which was more frequent $(63 \%)$ in those dying under 41 years of age than in those dying after this (24\%). About half the cases in each age group showed diffuse fibrous change (54\% and 53\% respectively) as compared with only 17 per cent in the younger control group. In the older control group this type of change was found in 47 per cent. 


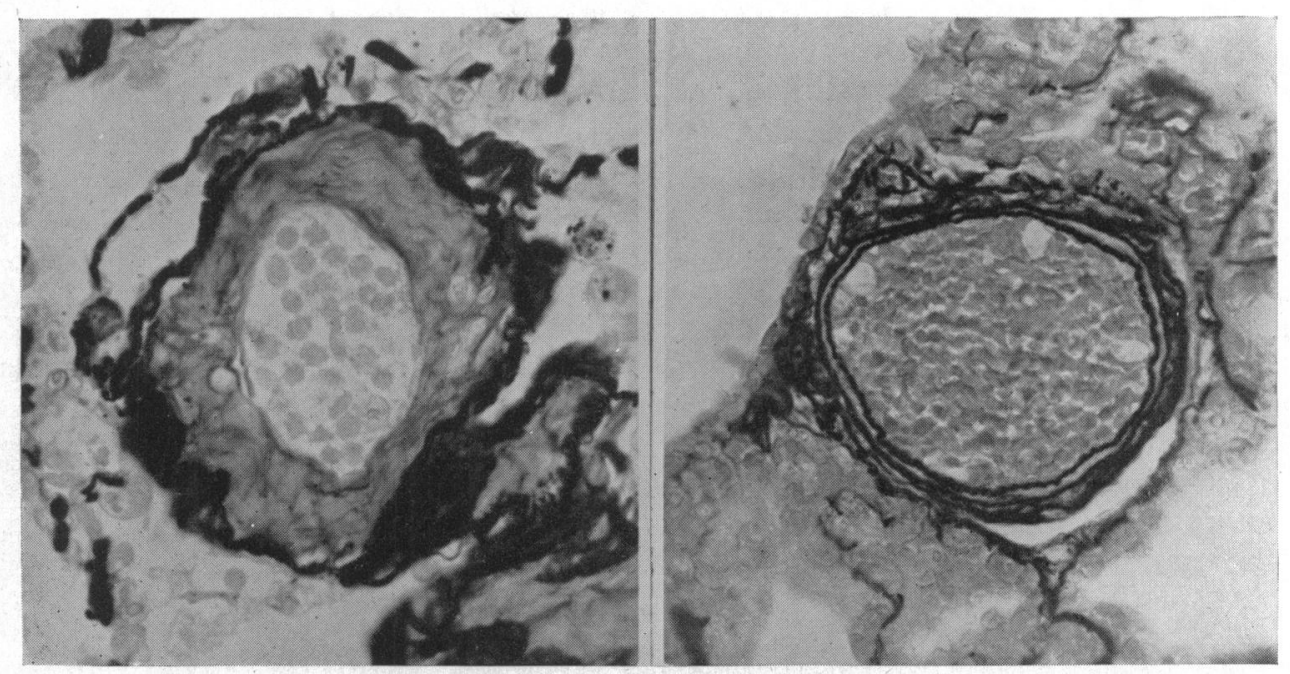

FIG. 3.-Gross fibrous intimal thickening of an arteriole or venule in a case of mitral stenosis. $\times 550$ : Hart-van Gieson.

FIG. 4.-Normal small pulmonary artery. The media is thin and bounded by well defined external and internal elastic laminæ. $\times$ 350: Hart-van Gieson.

TABLE I

Changes in Pulmonary Arterioles and Venules Related to Age at Death

\begin{tabular}{lll|c|c|c|c}
\hline & & $\begin{array}{c}\text { No change or } \\
\text { slight inconstant } \\
\text { change }\end{array}$ & \multicolumn{3}{|c}{ Diffuse change } \\
\cline { 5 - 7 } & & & Muscularization & Mixed & Fibrous \\
\hline Controls below 40 years &. &. & $24(83 \%)$ & 0 & 0 & $5(17 \%)$ \\
\hline Controls 41 years and over &. &. & $20(53 \%)$ & 0 & 0 & $18(47 \%)$ \\
\hline Mitral stenosis below 40 years &.. & $11(26 \%)$ & $9(21 \%)$ & $18(42 \%)$ & $5(12 \%)$ \\
\hline Mitral stenosis 41 years and over &.. & $25(40 \%)$ & $4(6 \%)$ & $11(18 \%)$ & $22(35 \%)$ \\
\hline
\end{tabular}

Figures in brackets show the percentage of the total number of cases in each group (approx.)

Table II relates the number of cases showing each type of change to the degree of mitral stenosis. In those with slight or doubtful stenosis no muscularization of arterioles was noted, but 27 per cent of those with moderate, 58 per cent of those with severe, and 80 per cent of those with gross stenosis showed muscular change.

Small Arteries. Small muscular arteries (Brenner, 1935) are vessels of 0.1-1 mm. external diameter with a media occupying 6-32 per cent of this measurement and consisting mainly of circularly directed smooth muscle cells with an occasional elastic fibril (Fig. 4). The media is bounded by well defined internal and external elastic laminae and the endothelial lining rests directly on the former.

Intimal thickening was commonly seen both in the mitral stenosis and in the control series and consisted usually in a segmental or circumferential splitting of the elastica interna to form one or more additional laminæ or layers of fibrils internal to it. A varying number of longitudinally directed muscle cells were present in the interstices. Fibrous tissue tended to replace this musculoelastic structure especially in cases dying in the later decades. 
TABLE II

Changes in Pulmonary Arterioles and Venules Related to Severity of Mitral Stenosis

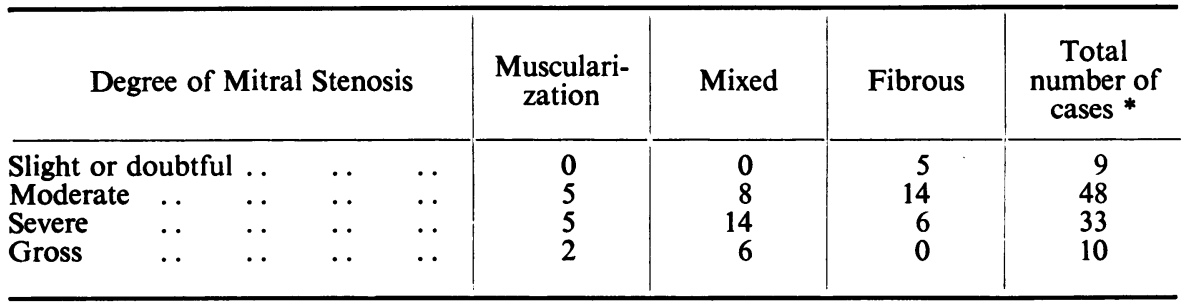

* In the remaining 5 cases, the degree of stenosis was not recorded (one showed muscularization, one mixed change, one fibrosis, and two an insignificant degree of change).

Changes in the media and especially muscular hypertrophy were difficult to interpret. It is uncertain whether all muscular arteries examined showed the same degree of terminal constriction or dilatation. Thus in some there was much crenation of elastic layers, suggesting that the lumen might be artificially reduced and the thickness of the wall increased. It was difficult at times to distinguish between hypertrophied small pulmonary arteries and bronchial arteries with condensation of elastic tissue around the periphery of the media simulating an external elastic lamina. However, in most cases with much muscularization of arterioles, medial hypertrophy of the small arteries was present (Fig. 5); points of narrowing of the media were seen in some of these hypertrophied vessels. Medial and intimal changes in the small arteries varied from vessel to vessel in the same section. Changes recorded in Table III represent at least reduplication of the elastica interna in the majority of vessels.

Intimal thickening in the controls exactly resembled that in the mitral stenosis series, but medial hypertrophy was not seen. Diffuse intimal thickening of the small muscular arteries occurred in 73 per cent of cases of mitral stenosis and in 59 per cent of the controls.

TABLE III

Changes in Small Muscular Arteries and Veins Related to Age at Death

\begin{tabular}{|c|c|c|c|c|c|c|c|}
\hline & & & & \multicolumn{2}{|c|}{ Small arteries } & \multicolumn{2}{|c|}{ Small veins } \\
\hline & & & & Controls & Mitral stenosis & Controls & Mitral stenosis \\
\hline $\begin{array}{l}\text { Below } 40 \text { years .. } \\
41 \text { years and over }\end{array}$ & $\begin{array}{l}\cdots \\
\cdots\end{array}$ & $\ddot{x}$ & $\ddot{x}$ & $\begin{array}{l}13(45 \%) \\
27(71 \%)\end{array}$ & $\begin{array}{l}23(53 \cdot 5 \%) \\
54(87 \%)\end{array}$ & $\begin{array}{r}4(14 \%) \\
29(76 \%)\end{array}$ & $\begin{array}{l}30(70 \%) \\
55(89 \%)\end{array}$ \\
\hline
\end{tabular}

Figures in brackets show percentage of total number of cases in each group (approx.)

Small Veins. Small pulmonary veins maintain the simple structure of the venule up to a diameter of about $0.2 \mathrm{~mm}$. The structure of the wall is always more irregular than that of the small arteries consisting of elastic fibres interspersed with connective tissue and a few muscle cells. The wall of vessels up to $1 \mathrm{~mm}$. in diameter only occupies 2-7 per cent of the external diameter and there is no well defined elastica externa, the media and adventitia tending to blend (Brenner, 1935).

Fibrous intimal thickening of small veins with a variable admixture of fibrillary elastic tissues was found to be a striking feature of cases of mitral stenosis (Fig. 6). Muscle cells were not prominent. In the control series similar changes were seen often to the same extent. Diffuse, wellmarked thickening was present in 81 per cent of cases of mitral stenosis examined and in 49 per cent of controls (Table III). The difference was greater in the younger group $(70 \%$ in cases under 40 with mitral stenosis compared with $14 \%$ of controls). 
Fig. 5.-Hypertrophy of the media of a small pulmonary artery in a case of mitral stenosis. Localized narrowing of the media is present at one point in its circumference and there is a little segmental musculo elastic intimal thickening. The adventitia is thickened. $\times 350$ : Hart-van Gieson.
FIG. 6.-Slight, uniform fibro elastic thickening of the intima of a small pulmonary vein. The irregular arrangement of elastic layers in the venous wall can be seen. $\times 350$ : Hart-van Gieson.

\section{Discussion}

Sclerotic changes occurring in the small pulmonary vessels with increasing age have been studied by Brenner (1935), Welch and Kinney (1948), and Neely (1949) among others. The change found in arterioles and venules was fibrous intimal thickening similar to that here described in both series. Musculo-elastic and fibrous intimal thickening of small arteries have been described in the absence of mitral stenosis and a good account of their development was given by Giroux (1910). Some authors (Eliaschewitz, 1931) have thought that the development of a layer of longitudinal smooth muscle fibres and elastic tissue represents a medial hypertrophy, but we consider this is present only when there is an increase in thickness of the circularly directed muscle. Sclerotic venous changes have received less attention but Brenner described intimal fibrosis with age and fibro-elastosis in congestive failure.

A variety of factors have been thought to play a part in the development of vascular sclerosis, but there is little evidence to support any as of primary or contributory importance, except age and pulmonary hypertension.

Those authors who have concerned themselves more specifically with the vascular changes occurring in mitral stenosis show little agreement as to their nature or significance. Yater and Constam (1928) described thickening of the media of the pulmonary " arterioles " in a case of mitral stenosis with emphysema, and thought this was a primary vascular change that was not related to the other lesions present.

Parker and Weiss (1936) examined 23 cases of mitral stenosis and found proliferative thickening of arteriolar walls with occasional necrotizing arteriolitis and medial hypertrophy of the small arteries: the prolonged action of high intravascular pressure, stagnation of blood flow, and œdema was thought to be of importance in producing these lesions. Larrabee et al. (1949) described medial atrophy of arterioles with fibrous intimal thickening and medial hypertrophy of small arteries with intimal thickening (fibrous or muscular). It is obvious that the same terminology is not used in all these papers. 
Our results show that two different processes occur in the small pulmonary vessels in mitral stenosis-(1) an increase in circularly directed muscle in the walls of vessels on the arterial side and (2) acceleration of the development of decrescent changes, best seen on the venous side. The first is seen chiefly as muscularization of arterioles-vessels that normally possess no media-but medial hypertrophy of small arteries also occurs. The origin of the new arteriolar muscle is uncertain. It might arise by hypertrophy of occasional muscle cells related to the elastic lamina or from more primitive mesenchymal cells. The irregular structure of the wall of the muscularized vessel suggests the presence of separate groups of circularly running fibres.

The higher incidence of the muscular type of change in cases dying under 40 years of aige suggests a direct relationship with the degree of stenosis, and when the proportion of cases showing arteriolar muscularization is related to the degree of mitral stenosis this is confirmed (Table II). Mitral stenosis leads to early pulmonary hypertension (Lenegre et al., 1948; Draper et al., 1951), which must be considered as a possible ætiological factor. Unfortunately the presence or absence of right ventricular hypertrophy is an inadequate basis for deductions of pulmonary pressure. However, since the small pulmonary arteries and arterioles become more like those of the systemic circulation and also those of the pulmonary circulation in the fœtus (Neely, 1949; Edwards and Chamberlain, 1951) increased intravascular pressure would seem to be of importance. Edwards and Chamberlain also found increased muscle development in congenital cardiac defects with a common ventricular outflow, confined to the small arteries. Finally, Neely (1949) has described similar vascular changes in emphysema and in kyphoscoliosis with right ventricular hypertrophy.

Fibrous intimal thickening of arterioles occurs with increasing age. Over the age of 40 years there is little difference in incidence in each series ( $47 \%$ of control and $53 \%$ of mitral stenosis cases), but below this age fibrous changes are more common in association with valvular disease $(17 \%$ of control and $54 \%$ of mitral stenosis cases). Since the same proportion of cases of mitral stenosis in both age groups showed fibrous arteriolar sclerosis there is probably little replacement of muscular change by fibrous change with advancing age.

Fibrous arteriolar thickening may be associated with reduced blood flow. Harrison (1948) described involutionary fibrous intimal thickening of vessels under $200 \mu$ external diameter following blocking of the parent vessel by thrombus material in rabbits. In our cases it was most marked in areas of collapsed or fibrosed lung or with great reduction of arterial lumina by intimal thickening, or healed thrombotic occlusion. No direct relationship was found between the frequency of this change and the degree of stenosis.

The onset of intimal changes in small arteries and veins is also accelerated by the presence of the valvular lesion, especially in the latter, although when gross intimal thickening only is considered the same proportions are found in each series (7\% of cases of mitral stenosis; $6 \%$ of controls). It seems possible that the fibro-elastic thickening of the venous intima might be hastened by overdistension or stagnation of blood following obstruction to free flow.

Some cases of well established mitral stenosis showed none of the above changes in the pulmonary vessels. Investigations of the autopsy records did not reveal any factor that might have prevented congestion in the pulmonary circulation or the development of pulmonary hypertension(e.g. valvular lesions on the right side of the heart; vascular pleural adhesions, permitting drainage into systemic veins) and right ventricular hypertrophy was present in some of them.

Narrowing of the small pulmonary arteries whatever its cause may help to maintain pulmonary hypertension by increasing resistance in the pulmonary circulation (Edwards and Chamberlain, 1951). Edwards and Burchell (1951) described medial hypertrophy and fibrous intimal thickening of small arteries in a case of pulmonary venous obstruction; they thought that the arterial changes might protect the pulmonary capillaries against excessively high pressures and suggested a similar mechanism in mitral stenosis.

Larrabee et al. believe that muscular hypertrophy of small arteries in cases of mitral stenosis would increase resistance to pulmonary blood flow, but that this change would be reversible after valvulotomy in the absence of intimal fibrosis or medial scarring. That pulmonary vascular resis- 
tance is actually increased in mitral stenosis has been confirmed by Draper et al. (1951) who calculated this factor from direct measurements of pulmonary blood pressure and blood flow: they also showed that the resistance fell following valvulotomy.

Our results confirm the labile nature of the important changes in the pulmonary arteries and arterioles and also suggest that a more effective nervous or humoral control of the pulmonary circulation could exist in mitral stenosis. This might help to maintain a raised pulmonary pressure, but would cease to operate with regression of the vascular changes after valvulotomy. Intimal thickening is probably of no importance in maintaining pulmonary hypertension since the same degree of change is seen in elderly subjects in whom there has been no evidence of raised pulmonary pressure.

\section{SUMMARY}

The small pulmonary arteries, arterioles, venules, and small veins were studied in 105 cases of mitral stenosis and compared with those in 67 controls in whom no known or suspected cause of pulmonary hypertension was present.

Diffuse muscularization of pulmonary arterioles associated in some cases with medial hypertrophy of the small arteries was present in $\mathbf{4 0}$ per cent of the mitral stenosis but in none of the control cases. The percentage of cases showing this was related to the severity of the stenosis. The development of decrescent changes in the pulmonary vessels especially on the venous side was found to be accelerated by mitral stenosis. In some cases of well established mitral stenosis, however, the small pulmonary vessels were normal.

The increased muscularity of small arteries and arterioles may help to maintain pulmonary hypertension, especially since the pulmonary arterial tree is probably rendered more susceptible to the action of neurogenic or humoral agencies tending to produce pulmonary hypertension. Increased resistance due to muscularization of arterioles is unlikely to persist following mitral valvulotomy. Intimal thickening of the small pulmonary vessels probably plays no part in maintaining pulmonary hypertension.

I would like to thank Professor Biggart for helpful advice and criticism throughout the preparation of this paper, Dr. J. F. Pantridge for suggesting the investigation, and Dr. R. A. Neely for allowing me full access to his thesis; also Mr. J. Davidson and Mr. D. Mehaffey for preparation of the histological material and photography.

\section{REFERENCES}

Brenner, O. (1935). Arch. intern. Med., 56, 211.

Draper, A., Heimbecker, R., Daley, R., Carroll, D., Mudd, G., Wells, R., Falholt, W., Andrus, E. C., and Bing, R.J. (1951). Circulation, 3, 531.

Edwards, J. E., and Burchell, H. B. (1951). Arch. intern. Med., 81, 372.

- and Chamberlain, W. B. (1951). Circulation, 3, 524.

Eliaschewitz, P. A. (1921). Virchows. Arch. Path. Anat., 279, 436.

Giroux, L. (1910). These de Paris, 149.

Harrison, C. V. (1948). J. Path. Bact., 60, 289.

Larrabee, W. F., Parker, R. L., and Edwards, J. E. (1949). Proc. Staff Meet. Mayo Clinic., $24,316$.

Lenegre, J., Maurice, P., and Scebat, L. (1948). Bull. Mem. Soc. Med Hôp. Paris, 52, 881.

Neely, R. A. (1949). Thesis (unpublished).

Parker, F. Jr., and Weiss, S. (1936). Amer. J. Path., 12, 573.

Posselt, A. (1909). Ergebn. Allg. Path. Path. Anat., 13, 298.

Welch, K. J., and Kinney, T. D. (1948). Amer. J. Path., 24, 729.

Yater, W. M., and Constam, G. R. (1929). Med. Clin. N. America, 12, 1689. 